\title{
Cerebral autoregulation in anoxic brain injury patients treated with targeted temperature management
}

\author{
Ilaria Alice Crippa ${ }^{1 *} \mathbb{0}$, Jean-Louis Vincent ${ }^{1}$, Federica Zama Cavicchi ${ }^{1}$, Selene Pozzebon ${ }^{1}$, Filippo Annoni ${ }^{1}$, \\ Antonella Cotoia ${ }^{1,2}$, Hassane Njimi ${ }^{1}$, Nicolas Gaspard ${ }^{3}$, Jacques Creteur ${ }^{1}$ and Fabio Silvio Taccone ${ }^{1}$
}

\begin{abstract}
Background: Little is known about the prevalence of altered CAR in anoxic brain injury and the association with patients' outcome. We aimed at investigating CAR in cardiac arrest survivors treated by targeted temperature management and its association to outcome.

Methods: Retrospective analysis of prospectively collected data. Inclusion criteria: adult cardiac arrest survivors treated by targeted temperature management (TTM). Exclusion criteria: trauma; sepsis, intoxication; acute intra-cranial disease; history of supra-aortic vascular disease; severe hemodynamic instability; cardiac output mechanical support; arterial carbon dioxide partial pressure $\left(\mathrm{PaCO}_{2}\right)>60 \mathrm{mmHg}$; arrhythmias; lack of acoustic window. Middle cerebral artery flow velocitiy (FV) was assessed by transcranial Doppler (TCD) once during hypothermia (HT) and once during normothermia (NT). FV and blood pressure (BP) were recorded simultaneously and Mxa calculated (MATLAB). Mxa is the Pearson correlation coefficient between FV and BP. Mxa $>0.3$ defined altered CAR. Survival was assessed at hospital discharge. Cerebral Performance Category (CPC) 3-5 assessed 3 months after CA defined unfavorable neurological outcome (UO).
\end{abstract}

Results: We included 50 patients (Jan 2015-Dec 2018). All patients had out-of-hospital cardiac arrest, 24 (48\%) had initial shockable rhythm. Time to return of spontaneous circulation was 20 [10-35] min. HT (core body temperature $33.7[33.2-34]^{\circ} \mathrm{C}$ ) lasted for 24 [23-28] h, followed by rewarming and NT (core body temperature: 36.9 [36.6-37.4] ${ }^{\circ} \mathrm{C}$ ). Thirty-one (62\%) patients did not survive at hospital discharge and 36 (72\%) had UO. Mxa was lower during HT than during NT (0.33 [0.11-0.58] vs. 0.58 [0.30-0.83]; $p=0.03$ ). During HT, Mxa did not differ between outcome groups. During NT, Mxa was higher in patients with $\cup O$ than others (0.63 [0.43-0.83] vs. 0.31 [ $-0.01-0.67] ; p=0.03$ ). Mxa differed among CPC values at NT ( $p=0.03$ ). Specifically, CPC 2 group had lower Mxa than CPC 3 and 5 groups. At multivariate analysis, initial non-shockable rhythm, high Mxa during NT and highly malignant electroencephalography pattern (HMp) were associated with in-hospital mortality; high Mxa during NT and HMp were associated with UO.

Conclusions: CAR is frequently altered in cardiac arrest survivors treated by TTM. Altered CAR during normothermia was independently associated with poor outcome.

Keywords: Post-anoxic brain injury, Neurological outcome, Temperature management

*Correspondence: ilaria.crippa@ulb.be; ilaria.alice.crippa@gmail.com ${ }^{1}$ Department of Intensive Care, Erasme Hospital, Université Libre de Bruxelles (ULB), Route de Lennik 808, 1070 Bruxelles, Belgium

Full list of author information is available at the end of the article

\section{Introduction}

Mortality and morbidity remain high after cardiac arrest (CA) [1]. Although survival rate has improved over the years [2], less than $10 \%$ of patients recover an original author(s) and the source, provide a link to the Creative Commons licence, and indicate if changes were made. The images or other third party material in this article are included in the article's Creative Commons licence, unless indicated otherwise in a credit line to the material. If material is not included in the article's Creative Commons licence and your intended use is not permitted by statutory regulation or exceeds the permitted use, you will need to obtain permission directly from the copyright holder. To view a copy of this licence, visit http://creativecommons.org/licenses/by/4.0/. The Creative Commons Public Domain Dedication waiver (http://creativeco mmons.org/publicdomain/zero/1.0/) applies to the data made available in this article, unless otherwise stated in a credit line to the data. 
intact neurological function [3]. The pathophysiology of hypoxic-ischemic brain injury involves microvascular dysfunction, micro-thrombosis, vasogenic and cytotoxic edema, neuronal cell dysfunction and excitoxicity [4-6]. Reduction of cerebral blood flow (CBF) in the presence of arterial hypotension has been suggested as a potential contributor to secondary damage $[7,8]$, although CBF assessment is rarely performed in clinical practice.

Current guidelines underline the importance of postresuscitation care in preventing secondary brain injury. Targeted temperature management (TTM) remains the only neuroprotective strategy, although its effectiveness remains controversial [9]. Maintaining an adequate CBF and cerebral oxygen delivery appears an appealing strategy [10]. Although it is recommended to keep mean arterial blood pressure (MAP) above $65 \mathrm{mmHg}$, such target may not guarantee an adequate cerebral perfusion in CA patients. In fact, pressure-cerebral autoregulation (CAR), which is an active mechanisms that maintains a constant CBF through changes in the diameter of cerebral arterioles within a wide range (i.e., $50-150 \mathrm{mmHg}$ ) of MAP in healthy individuals [11], might be altered after an acute illness [12-14]. As such, changes in MAP would lead to directly proportional modifications in $\mathrm{CBF}$, with the risk of either cerebral hypoperfusion or hyperemia. Altered CAR has been reported in CA patients $[7,8,15-17]$ and associated with poor outcome $[8,15]$. However, some of these studies were conducted before of the TTM era and differed in methods to assess CAR.

The aim of this study was to investigate changes in CAR over time in patients treated with TTM after CA. Secondarily, we aimed to assess the prognostic role of CAR on patients' outcome.

\section{Methods}

Study population Data of patients admitted to our Department of Intensive Care after CA were included into a prospective registry (approved by the Ethics Committee, who waived informed consent-P2015/394). CAR was assessed routinely in brain-injured patients by use of transcranial Doppler (TCD), except in case of: traumatic brain injury (TBI); sepsis, drug intoxication; acute intra-cranial disease; previous intra or extra-cranial vascular surgery; MAP $<50 \mathrm{mmHg}$; extra corporeal membrane oxygenation, intra-aortic balloon pump counter-pulsation; arterial carbon dioxide partial pressure $\left(\mathrm{PaCO}_{2}\right)>60 \mathrm{mmHg}$; cardiac arrhythmias; lack of acoustic window. This study (P2018/234) retrospectively included all patients $>18$ years admitted from January 2015 to December 2018, treated by TTM and with available CAR data.

Patients' management Patients unresponsive after return of spontaneous circulation (ROSC), without contraindication, underwent induction of hypothermia (HT, core temperature $32-34{ }^{\circ} \mathrm{C}$ ) for at least $24 \mathrm{~h}$ with subsequent rewarming not faster than $0.25{ }^{\circ} \mathrm{C}$ per hour. Following rewarming, core body temperature $>38^{\circ} \mathrm{C}$ was treated. Patients were mechanically ventilated; sedation and neuro-muscular blocking agents (NMBA) were provided as needed. Invasive arterial blood pressure (BP) was monitored in radial or femoral artery. Temperature was invasively monitored (pulmonary artery catheter, $\left.\mathrm{PiCCO}^{\circledR}\right)$. All patients had continuous electroencephalogram (cEEG) monitoring according to the International 10 to 20 system as soon as possible after admission, for at least $48 \mathrm{~h}$ and as long as clinically necessary.

$T C D$. TCD was performed once during HT and once during normothermia (NT, core body temperature $>36.5{ }^{\circ} \mathrm{C}$ ). Left or right middle cerebral artery (MCA) was identified [18] with a $2-\mathrm{MHz}$ probe, which was held in place using a plastic device (DWL, Germany. Blood flow velocity (FV) in MCA and BP were recorded simultaneously (DWL, Germany). TCD was performed when the patient was in steady state condition, avoiding any stimuli, modifications of vasoactive drugs, sedation, fluidic therapy or ventilator settings, 14 [9-18] h (HT) and 38 [36-45] h (NT) from admission. Arterial blood gas analysis (ABG), use of sedatives and NMBA, respiratory setting and use of cardio-active medications (i.e., inotropic agents or vasopressors) were recorded. cEEG were reviewed by a neurophysiologist (NG) and classified according to the American Clinical Neurophysiology Society definitions [19]. If suppressed or burst-suppression background were observed anytime during the monitoring, cEEG was classified as "highly malignant pattern" (HMp) [20,21]. The highest value of neuron-specific enolase (NSE) over the first $72 \mathrm{~h}$, since ICU admission was recorded. Survival was assessed at hospital discharge. Cerebral Performance Category scale (CPC) 3 months after CA was recorded from follow-up consultations. Unfavorable neurological outcome (UO) was defined as CPC 3-5, favorable outcome (FO) as CPC 1-2.

Cerebral autoregulation analysis $\mathrm{FV}$ and $\mathrm{BP}$ recordings were downloaded on a personal computer. Artifacts were identified as FV and BP values exceeding 3 standard deviations (MATLAB, USA) and visually inspected. In case of artefacts, the entire cardiac cycle was discarded. Recordings were artifacts were $>20 \%$ were discarded from analysis. CAR was assessed using Mxa index [22]; Mxa is the Pearson's correlation coefficient between BP and FV, averaged on a $10 \mathrm{~s}$ moving window with $50 \%$ overlap. Mxa $>0.3$ defined altered CAR [12].

Study outcomes The primary outcome was the differences in Mxa values and the proportion of patients with altered CAR between UO and FO. Secondary outcomes included: the differences in Mxa values and the 
proportion of patients with altered CAR between survivors and non-survivors; the predictive role of Mxa for hospital mortality and UO; the association between Mxa, highly malignant cEEG and NSE values.

Statistical analysis Statistical analysis was performed using $\mathrm{R}$ statistical software version 4.0.3 (R Foundation for Statistical Computing), Prism (GraphPad Software Inc.) and SAS software (SAS Institute Inc.). Characteristics of population are described as median [IQRs] or counts (\%). Shapiro-Wilk test was used to assess normality of data. Data were compared using Mann-Whitney test, Wilcoxon rank test, Kruskal-Wallis test or Fisher Exact test as appropriate. Difference in Mxa values among CPC groups was tested by one-way ANOVA with Tukey post hoc analysis. Correlation between Mxa and NSE was assessed using Spearman coefficient. In the multivariable analyses, considering the limited number of events, the predictor variables that were highly collinear within and across outcome and the risk of overfitting, we constructed predictive models for each outcome using tenfold cross validation with penalized logistic regression [23] (providing odds ratio and 95\% confidence intervals) and, as a sensitivity analysis, using generalized linear model via regularized regression with elastic net. Elastic net regression is controlled by two parameters, (1) alpha, which sets the degree of mixing between two extremes of regularized regression, and (2) lambda, defining the strength of regularization [24]. Linearity of the continuous variables with respect to the logit of the dependent variable was assessed via the Box-Tidwell procedure. Presence of outliers were assessed by studentized residuals. Collinearity between variables was assessed by variance inflation factor. All test are two tailed and the statistical significance was set at the $5 \%$ level.

\section{Results}

\section{Study population}

Out of 194 patients admitted over the study period, 50 were available for the analysis and 144 were excluded ( $n=12$ not treated with TTM; $n=4$ TBI or acute intracranial disease; $n=13$ previous stroke or neurological disease; $n=10$ hemodynamic instability: $n=22$ ECMO; $n=8$ elevated $\mathrm{PaCO}_{2} ; n=28$ cardiac arrhythmias, $n=18$ lack of acoustic window; $n=29$ lack of TCD operator). All patients had out-of-hospital CA. Shockable rhythm was recorded in 24 (48\%) patients. Time to ROSC was 20 [10-35] min. HT (core temperature $33.7[33.2-34]{ }^{\circ} \mathrm{C}$ ) lasted for 24 [23-28] h. During HT, all patients were sedated and $41(82 \%)$ were on NMBA; during NT (core temperature 36.9 [36.6-37.4] $\left.{ }^{\circ} \mathrm{C}\right), 25(50 \%)$ patients were on sedation and $8(16 \%)$ on NMBA. Thirty-one (62\%) patients did not survive at hospital discharge. Of those, 23 (74\%) died because of severe post-anoxic brain injury, while in 8 (26\%) patients, complete prognostication was not completed and death occurred because of multiple organ failure. Overall, 36 patients $(72 \%)$ had UO at 3 months: $5(10 \%)$ patients had CPC 3 and $31(62 \%)$ patients had CPC 5. Nine patients (18\%) had full neurological recovery (CPC 1$)$ and 5 patients (10\%) had CPC 2.

\section{Cerebral autoregulation and outcomes}

Mxa was lower during HT than during NT (0.33 [0.110.58 ] vs. 0.58 [0.30-0.83]; $p=0.03$-Additional file 1 : Table S1). Altered CAR was more frequent during NT than during HT (76\% vs. $54 \%$; $p=0.03-$ Fig. 1$)$. During HT, Mxa values and the proportion of patients with altered CAR were similar between patients with UO and FO (Table 1). During NT, patients with UO had higher Mxa values $(0.63$ [0.43-0.83] vs. 0.31 [- $0.01-$ 0.67]; $p=0.03$ ) and were more likely to have altered CAR compared to others (Table 1; Fig. 1). Values of clinical variables during normothermia in different outcome groups are reported in Table 2. Mxa values and the proportion of patients with altered CAR at NT differed among CPC scale values $(p=0.03$ and $p=0.02$, respectively-Fig. 2). CPC 2 had lower Mxa than CPC 3 and 5 groups. Four outliers in Mxa values were identified: one patient in the CPC 5 group had Mxa $=-0.40$, three patients in CPC 1 group had Mxa $=0.90,0.91$ and 0.96 , respectively. The outlier in the CPC 5 group with preserved CAR died because of MOF on high dose of cardio-active medication; 2 outliers in the CPC 1 group had $\mathrm{PaCO}_{2}$ between 50 and $60 \mathrm{mmHg}$, while the other had no clear explanation for high Mxa value. When Mxa analysis was performed excluding the first 3 outliers, patients with CPC 1,2 and 3 had significantly lower Mxa values than CPC 5 subgroup ( $p<0.01$ for comparison between CPC 1-2 and CPC $5, p=0.017$ for comparison between CPC 3 and CPC 5-Additional file 1: Table S3).

During HT, Mxa values and the proportion of patients with altered CAR were similar between non-survivors (NS) and survivors (SU) (Table 1). At NT, Mxa values were significantly higher in NS when compared to SU (0.67 [0.46-0.84] vs. 0.31 [0.00-0.62]; $p<0.01-$ Table 1$)$ and altered CAR was observed more frequently in NS than SU (Table 1, Fig. 1).

Patients with highly malignant cEEG pattern (HMp) $(n=18)$ had higher Mxa values at NT than others $(0.78$ [0.56-0.85] vs. $0.41[0.10-0.77] ; p=0.04)$. There was a correlation between NSE and Mxa at NT $(r=0.38$ [95\% CI 0.02-0.64]; $p=0.02)$ but not at HT $(r=0.26$ [95\% CI $-0.12-0.56$ ]; $p=0.17-$ Fig. 3$)$. Such results was confirmed when one very high value $(=383 \mathrm{ng} / \mathrm{mL})$ was 


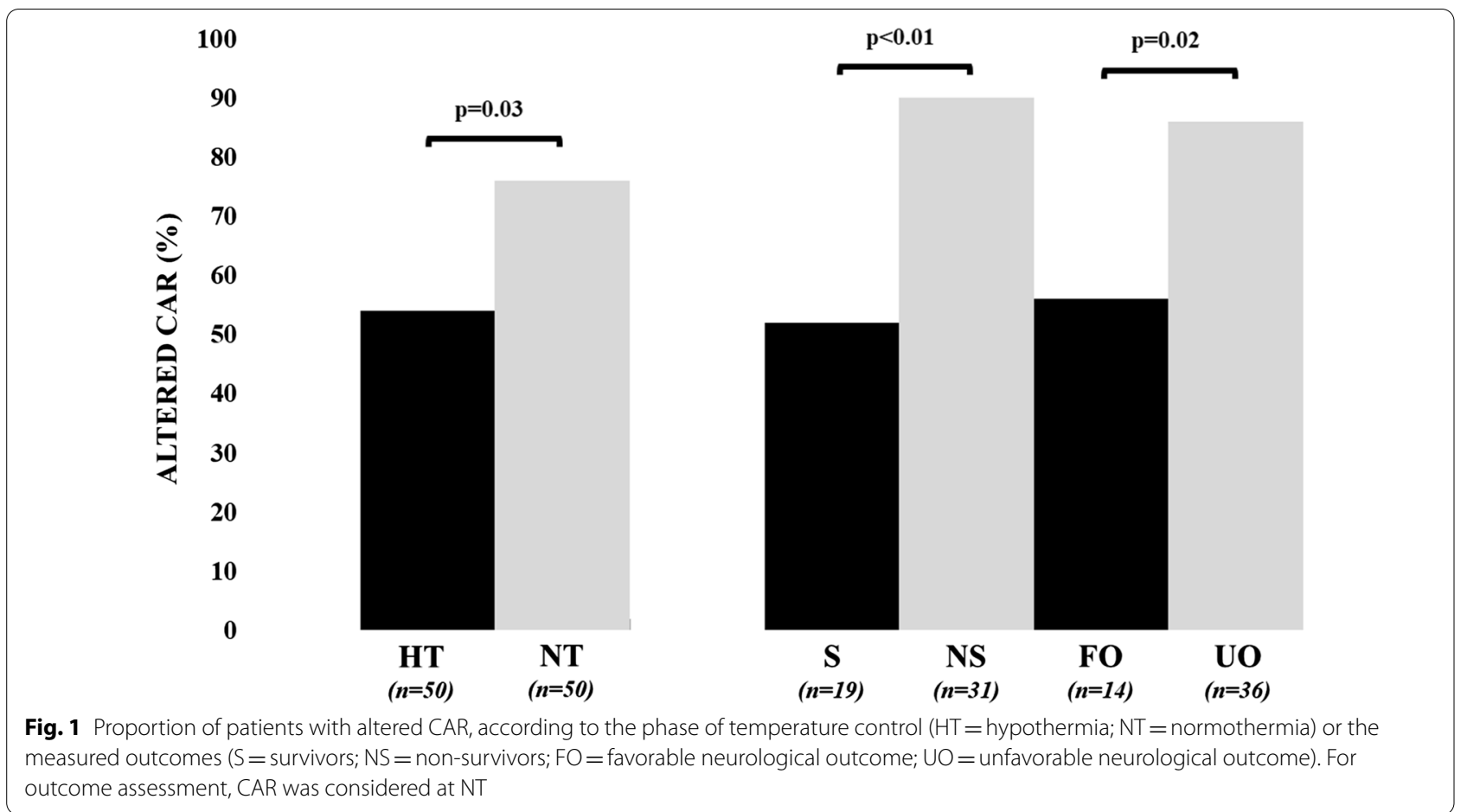

excluded from the analysis (at HT, $r=0.18 ; p=0.32$-at NT, $r=0.32 ; p=0.04$ ).

\section{Multivariable analyses}

In the penalized logistic regression analysis, high Mxa during NT and HMp were associated with UO; the fitted model correctly classified $84 \%$ of patients (Sn 71.4\%; Sp 97.2\%). Using the same approach, initial non-shockable rhythm, high Mxa during NT and HMp were associated with in-hospital mortality (Table 3); the model correctly classified 81\% of patients (Sn 68.4\%; Sp 93.5\%). Similar results were observed using regularized regression models with elastic net (Additional file 1: Table S4).

\section{Discussion}

This study showed that CAR is altered in CA patients treated by TTM, more often during normothermia than during hypothermia. Altered CAR during normothermia was more frequent among patients with poor outcomes. High Mxa values, thus worse CAR, were independently associated with hospital mortality and predictors of poor neurological recovery, such as highly malignant patterns on cEEG and high NSE values.

Our results are consistent with previous studies [7, $8,15-17,25]$. Sundgreen et al. showed that CAR was altered in 8 out of $18 \mathrm{CA}$ patients and the lower limit of CAR range was higher compared to healthy volunteers [7]. Ameloot et al. showed that altered CAR assessed by near infrared spectroscopy (NIRS) during the first $24 \mathrm{~h}$ of TTM was associated with poor neurological outcome and that MAP below the optimal CAR range was associated with mortality in $51 \mathrm{CA}$ patients [8]. In another study ( $n=23$ ) body temperature was kept around $36{ }^{\circ} \mathrm{C}$ and altered CAR during the first 3 days after hospital admission was associated with mortality; however, CAR values did not change over time among survivors and non-survivors [15]. Similar CAR alteration was reported within $24 \mathrm{~h}$ from admission in $20 \mathrm{CA}$ patients who underwent TTM at different target temperatures [25].

In this study, altered CAR after CA independently predicted poor outcome. However, whether altered CAR is a marker of brain injury or a contributing factor to outcome remains unclear; CAR was preserved early after $\mathrm{CA}$, while altered in non-survivors and patients with UO at NT. Moreover, Mxa values at NT correlated with the highest NSE values during ICU stay, generally obtained 48-72 $\mathrm{h}$ after injury [26]. These findings suggest that altered CAR might result in altered cerebral perfusion inducing secondary brain damage in these patients. In previous studies, lower limit of CAR was right-shifted and the range of effective CAR narrowed after CA [7, $8,15]$. Furthermore, although the association between maintenance of MAP within CAR range and neurological recovery has not be determined [27], the amount of time spent at MAP outside CAR ranges has been associated with UO [8]. As MAP didn't differ between HT and 
Table 1 Characteristics of the study cohort according to outcomes

\begin{tabular}{|c|c|c|c|c|c|c|c|}
\hline & All $(n=50)$ & Survivors $(n=19)$ & $\begin{array}{l}\text { Non-Survivors } \\
(n=31)\end{array}$ & $p$ value & $\mathrm{FO}(n=14)$ & UO $(n=36)$ & $p$ value \\
\hline Male gender, $n(\%)$ & $39(78)$ & $15(79)$ & $24(77)$ & 1.00 & $11(79)$ & $28(79)$ & 1.00 \\
\hline Age, years & 65 [55-73] & $60[51-71]$ & $67[55-74]$ & 0.33 & $58[51-73]$ & 66 [57-73] & 0.40 \\
\hline APACHE ॥ & $26[24-31]$ & 26 [21-28] & 27 [24-33] & 0.07 & 26 [21-28] & 27 [24-32] & 0.17 \\
\hline ICU LOS, days & $9[4-19]$ & $22[11-37]$ & $4[3-10]$ & $<0.01$ & $18[9-31]$ & $6[3-13]$ & $<0.01$ \\
\hline \multicolumn{8}{|l|}{ Comorbidities } \\
\hline $\begin{array}{l}\text { Arterial hyperten- } \\
\text { sion, } n(\%)\end{array}$ & $23(46)$ & $7(37)$ & $16(52)$ & 0.39 & $5(36)$ & $18(50)$ & 0.53 \\
\hline $\begin{array}{l}\text { Vascular disease, } \\
n(\%)\end{array}$ & $10(20)$ & $3(16)$ & $7(23)$ & 0.72 & $3(21)$ & $7(19)$ & 1.00 \\
\hline $\begin{array}{l}\text { Chronic heart failure, } \\
n(\%)\end{array}$ & $3(6)$ & $0(0)$ & $3(10)$ & 0.28 & $0(0)$ & $3(8)$ & 0.55 \\
\hline $\begin{array}{l}\text { Chronic kidney } \\
\text { disease, } n(\%)\end{array}$ & $8(16)$ & $2(11)$ & $6(19)$ & 0.69 & $1(7)$ & $7(19)$ & 0.41 \\
\hline COPD, $n(\%)$ & $6(12)$ & $2(11)$ & $4(13)$ & 1.00 & $0(0)$ & $6(17)$ & 0.17 \\
\hline $\begin{array}{l}\text { Diabetes mellitus, } \\
n(\%)\end{array}$ & $10(20)$ & $3(30)$ & $7(70)$ & 0.72 & $1(7)$ & $9(25)$ & 0.25 \\
\hline $\begin{array}{l}\text { Previous Seizure, } \\
n(\%)\end{array}$ & $3(6)$ & $0(0)$ & $3(10)$ & 0.28 & $0(0)$ & $3(8)$ & 0.55 \\
\hline Minor stroke, $n(\%)$ & $7(14)$ & $2(11)$ & $5(16)$ & 0.70 & $1(7)$ & $6(17)$ & 0.66 \\
\hline \multicolumn{8}{|c|}{ Cardiac arrest characteristics } \\
\hline \multicolumn{8}{|c|}{ Cause of CA, $n(\%)$} \\
\hline Cardiac & $23(48)$ & $13(68)$ & $10(32)$ & 0.02 & $10(71)$ & $13(36)$ & 0.03 \\
\hline Anoxic & $15(32)$ & $2(11)$ & $13(42)$ & 0.03 & $1(7)$ & $14(39)$ & 0.04 \\
\hline Obstructive & $2(6)$ & $1(5)$ & $1(3)$ & 1.00 & $1(7)$ & $1(3)$ & 0.49 \\
\hline Indeterminate & $9(18)$ & $4(22)$ & $7(10)$ & 0.30 & $2(14)$ & $8(26)$ & 0.30 \\
\hline $\begin{array}{l}\text { Shockable rhythm, } \\
n(\%)\end{array}$ & $24(48)$ & $14(58)$ & $10(42)$ & $<0.01$ & $10(71)$ & $14(39)$ & 0.06 \\
\hline Time to ROSC, min & 20 [10-35] & 16 [10-35] & $23[16-35]$ & 0.09 & 13 [10-33] & 22 [16-36] & 0.03 \\
\hline \multicolumn{8}{|c|}{ Clinical variables and autoregulation assessment } \\
\hline $\mathrm{NSE}(\mathrm{ng} / \mathrm{mL})$ & $39[24-78](n=32)$ & $29[20-40](n=14)$ & $74[34-108](n=18)$ & $<0.01$ & $25[20-37](n=10)$ & $56[32-86](n=22)$ & 0.01 \\
\hline $\begin{array}{l}\text { Highly malignant } \\
\text { EEG }\end{array}$ & $18(36)$ & $0(0)$ & $18(58)$ & $<0.01$ & $0(0)$ & $18(50)$ & $<0.01$ \\
\hline Mxa during $\mathrm{HT}$ & $0.33[0.11-0.58]$ & $0.37[0.03-0.51]$ & $0.31[0.18-0.65]$ & 0.25 & $0.21[0.00-0.46]$ & $0.38[0.18-0.65]$ & 0.08 \\
\hline Mxa during NT & $0.58[0.30-0.83]$ & $0.31[0.00-0.62]$ & $0.67[0.46-0.84]$ & $<0.01$ & $0.31[-0.01-0.69]$ & $0.63[0.43-0.83]$ & 0.03 \\
\hline $\begin{array}{l}\text { Altered CAR at HT, } \\
n(\%)\end{array}$ & $27(54)$ & $11(42)$ & $17(52)$ & 0.77 & $7(50)$ & $20(56)$ & 0.76 \\
\hline $\begin{array}{l}\text { Altered CAR at NT, } \\
n(\%)\end{array}$ & $38(76)$ & $10(53)$ & $28(90)$ & $<0.01$ & $7(50)$ & $31(86)$ & 0.02 \\
\hline
\end{tabular}

APACHE II acute physiology and chronic health evaluation II, CA cardiac arrest, CAR cerebral autoregulation, COPD chronic obstructive pulmonary disease, FO favorable outcome, HT hypothermia, LOS length of stay, Mxa mean flow index, NS non survivors, NT normothermia, ROSC return of spontaneous circulation; S survivors, UO unfavorable outcome

NT nor at NT between groups of patients with different outcomes, assessing autoregulation to individualize MAP values according to Mxa values rather than targeting predefined MAP targets (i.e., $>65 \mathrm{mmHg}$ ) may be beneficial in clinical settings.

The mechanisms underlying the impairment of CAR after CA are unclear, but involvement of cerebral vasculature is likely. During the first $12 \mathrm{~h}$ after CA, vascular resistances are often increased, while they decrease $24 \mathrm{~h}$ from resuscitation (i.e., secondary hyperemia) with CBF returning to normal values after $24 \mathrm{~h}$ from CA [28-30]. After $24 \mathrm{~h}$ from $\mathrm{CA}$, low cerebrovascular resistances and high CBF have been associated with poor prognosis [31, 32]. In this study, abnormal Mxa values were more likely to be observed during NT. The vasodilation that accompanies the late hyperemic response could be responsible of the reduced vasoactive tone and loss of response to BP fluctuations, i.e., loss of CAR. Experimental studies 
Table 2 Clinical and biological variables during the normothermic phase of TTM, according to outcomes

\begin{tabular}{|c|c|c|c|c|c|c|}
\hline & Survivors $(n=19)$ & $\begin{array}{l}\text { Non-survivors } \\
(n=31)\end{array}$ & $p$ value & FO $(n=14)$ & UO $(n=36)$ & $p$ value \\
\hline Sedatives, $n$ (\%) & $6(31)$ & $19(61)$ & 0.08 & $4(29)$ & $21(58)$ & 0.11 \\
\hline NMBA, $n(\%)$ & $1(5)$ & $7(23)$ & 0.13 & $1(7)$ & $7(19)$ & 0.41 \\
\hline $\begin{array}{l}\text { Mechanical venti- } \\
\text { lation, } n(\%)\end{array}$ & $8(42)$ & $26(84)$ & $<0.01$ & $3(21)$ & $31(86)$ & $<0.01$ \\
\hline MAP, mmHg & 77 [70-89] & 75 [70-83] & 0.47 & 81 [70-91] & 75 [70-85] & 0.37 \\
\hline Heart rate, bpm & 91 [68-111] & 88 [78-103] & 0.82 & 93 [66-108] & 88 [78-106] & 0.65 \\
\hline Temperature, ${ }^{\circ} \mathrm{C}$ & $37.0[36.8-37.4]$ & 36.8 [36.4-37.1] & 0.08 & $37.1[37.0-37.5]$ & $36.8[36.5-37.1]$ & 0.04 \\
\hline Hemoglobin, g/dL & $12.2[10.7-14.0]$ & 10.8 [8.9-12.8] & 0.17 & $11.9[10.5-14.0]$ & 11.5 [9.3-13.7] & 0.68 \\
\hline PEEP, $\mathrm{cmH}_{2} \mathrm{O}$ & $5[5-8]$ & $6[5-10]$ & 0.46 & $5[5-9]$ & $6[5-10]$ & 0.51 \\
\hline $\mathrm{FiO}_{2}$ & $0.4[0.3-0.5]$ & $0.3[0.3-0.5]$ & 0.16 & $0.4[0.3-0.5]$ & $0.3[0.3-0.5]$ & 0.25 \\
\hline $\mathrm{pH}$ & 7.36 [7.32-7.39] & $7.40[7.35-7.42]$ & 0.20 & 7.38 [7.34-7.39] & 7.4 [7.33-7.42] & 0.88 \\
\hline $\mathrm{PaCO}_{2}, \mathrm{mmHg}$ & $39[37-40]$ & $36[34-40]$ & 0.02 & $39[37-42]$ & 37 [34-40] & 0.07 \\
\hline $\mathrm{PaO}_{2}, \mathrm{mmHg}$ & 83 [70-92] & 80 [72-91] & 0.74 & 85 [76-94] & 80 [71-91] & 0.43 \\
\hline $\mathrm{ScvO}_{2}, \%$ & 75 [72-79] & 75 [73-78] & 0.82 & 75 [72-79] & 75 [72-78] & 0.83 \\
\hline Lactate, mmol/L & $1.3[1.0-2.0]$ & $1.3[1.0-2.3]$ & 0.66 & $1.3[1.0-1.7]$ & $1.3[1.0-2.4]$ & 0.37 \\
\hline $\begin{array}{l}\text { Time to TCD } \\
\text { assessment, hours }\end{array}$ & 38 [35-43] & 38 [36-46] & 0.78 & 39 [36-42] & 38 [32-48] & 0.98 \\
\hline $\begin{array}{l}\text { Cardio-active } \\
\text { medications, } n \text { (\%) }\end{array}$ & $9(47)$ & $23(74)$ & 0.07 & $6(43)$ & $26(72)$ & 0.10 \\
\hline
\end{tabular}

$\mathrm{FiO}_{2}$ fraction of inspired oxygen, $\mathrm{FO}$ favorable outcome, $M A P$ mean arterial pressure, NMBA neuromuscular blocking agents, $P E E P$ positive end-expiratory pressure, $\mathrm{PaCO}_{2}$ carbon dioxide arterial partial pressure, $\mathrm{PaO}_{2}$ oxygen arterial partial pressure, $\mathrm{ScVO}_{2}$ central venous oxygen saturation, $T C D$ transcranial Doppler, $U \mathrm{O}$ unfavorable outcome

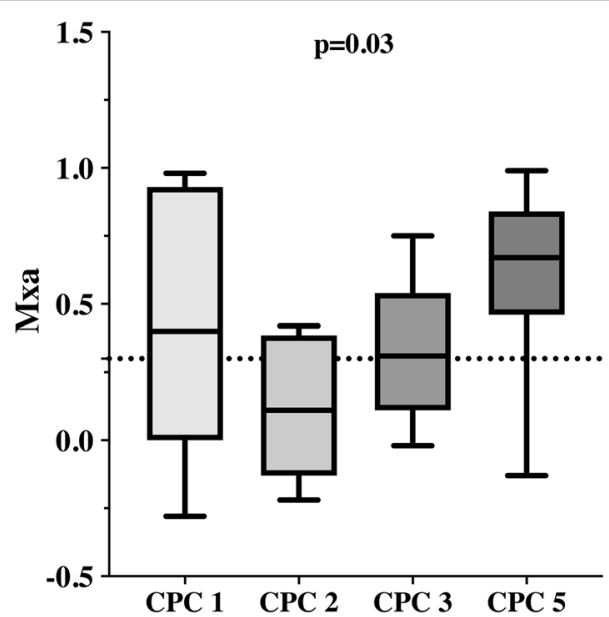

Fig. 2 Mxa at NT, according to the different CPC. Mxa was 0.40 [0.00-0.92] in patients with CPC 1, 0.11 [ - 0.13-0.39] in patients with CPC 2, 0.31 [0.17-0.43] in patients with CPC 3, 0.67 [0.46-0.84] in patients with CPC $5(p<0.01)$. CAR was altered in 5/9 $(56 \%)$ patients with CPC 1, 2/5 (40\%) patients with CPC 2, 3/5 (60\%) patients with CPC 3 and 28/31 (90\%) patients with CPC $5 p=0.02$ )

suggest that moderate decrease in core body temperature might be associated to an extended range of CAR [33]. Lavinio et al. showed that rewarming was associated with altered CAR in 24 patients cooled for refractory intracranial hypertension following TBI [34]. An inverse correlation between temperature and effectiveness of CAR has been suggested in CA patients treated with TTM targeting either $33{ }^{\circ} \mathrm{C}, 36{ }^{\circ} \mathrm{C}$ or not treated with TTM [25]. Given the association between time and temperature in this study, it is not possible to infer whether the modifications in CAR are associated to the progression of brain damage or to the effect of temperature on brain homeostasis. No specific studies on the role of TTM on CAR in CA patients has been performed so far. However, a potential protective role of TTM on preserving the reactivity of brain vasculature after anoxic brain injury cannot be excluded. These findings should, therefore, increase the awareness of clinicians on the importance of an accurate management of temperature after rewarming from moderate hypothermia, as this might have an impact on cerebral perfusion. Future studies comparing patients with or without TTM after CA are necessary to understand the role of temperature on CAR in CA patients.

Regulation of CBF is a complex phenomenon, which depends on the interaction between metabolism and pressure regulation. Neuronal metabolism is probably the chief drive in modifying $\mathrm{CBF}$, while the myogenic mechanism keeps CBF constant in case of modifications in cerebral perfusion pressure [35]. Data on CAR in case of altered metabolic demand are not univocal. 

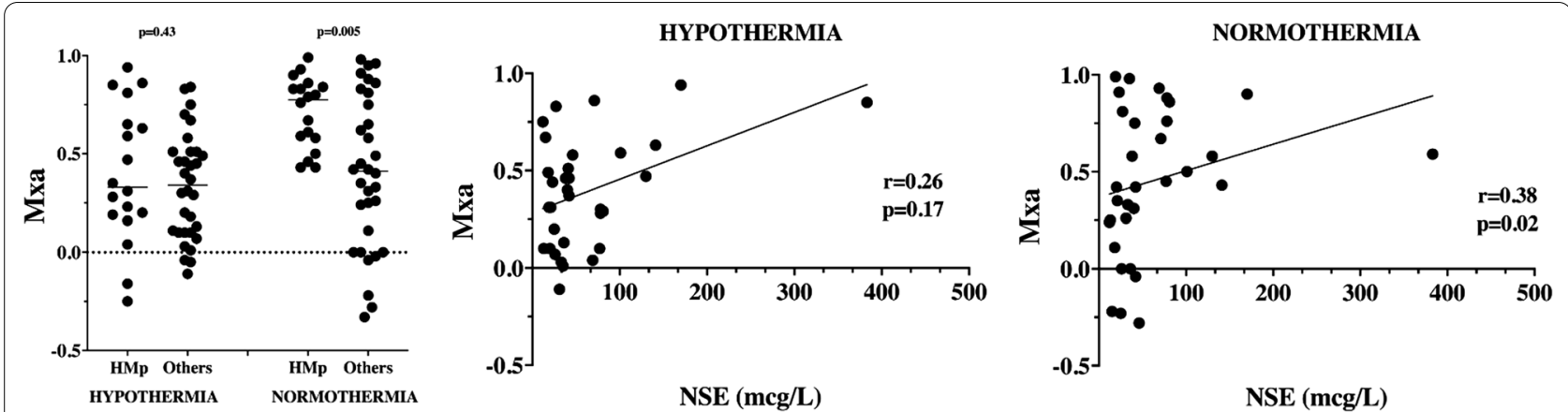

Fig. 3 Mxa according to the presence of highly malignant cEEG pattern ( $\mathrm{HMp}$ ); correlation between Mxa and the highest neuron specific enolase (NSE) values at hypothermia and normothermia

Table 3 Penalized logistic regression cross validation of predictive models

\begin{tabular}{|c|c|c|c|c|}
\hline & \multicolumn{2}{|l|}{ Mortality } & \multicolumn{2}{|c|}{ Unfavourable outcome } \\
\hline & $\mathrm{OR}(\mathrm{Cl})$ & $p$ value & $\mathrm{OR}(\mathrm{Cl})$ & $p$ value \\
\hline Age & $1.04(0.96-1.12)$ & 0.347 & $1.02(0.95-1.11)$ & 0.550 \\
\hline Arterial hypertension & $3.73(0.69-20.16)$ & 0.126 & $3.03(0.63-14.64)$ & 0.68 \\
\hline Shockable rhythm & $0.15(0.03-0.82)$ & 0.029 & $0.44(0.09-2.15)$ & 0.312 \\
\hline Time to ROSC & $1.01(0.92-1.09)$ & 0.909 & $1.01(0.93-1.10)$ & 0.809 \\
\hline Cardio-active medications & $2.54(0.47-13.75)$ & 0.279 & $1.80(0.37-8.74)$ & 0.463 \\
\hline $\mathrm{pCO}_{2}(\mathrm{mmHg})$ & $0.86(0.72-1.02)$ & 0.088 & $0.87(0.73-1.05)$ & 0.156 \\
\hline EEG HMp & $16.42(2.06-130.96)$ & 0.008 & $10.01(1.23-81.34)$ & 0.031 \\
\hline Mxa & $1.04(1.01-1.07)$ & 0.011 & $1.03(1.01-1.06)$ & 0.049 \\
\hline
\end{tabular}

The fitted models showed an accuracy of $84 \%$ (Cl 71-93\%), a sensitivity of $68 \%$ and a specificity of $94 \%$ for mortality, and an accuracy of $86 \%$ (Cl $73-94 \%)$, a sensitivity of $100 \%$ and a specificity of $50 \%$ for unfavourable outcome. CI confidence interval, EEG HMp highly malignant electroencephalography during ICU stay, Mxa mean flow index during normothermia, $\mathrm{OR}$ odds ratio, $p \mathrm{CO}_{2}$ arterial carbon dioxide partial pressure during normothermia, $R O S \mathrm{C}$ return of spontaneous circulation. Cardioactive medications: noradrenaline (norepinephrine) and/or dobutamine

Epileptic activity increases the diameter of the vessel supplying spiking neurons, thus increasing CBF [36]. Altered CAR has been documented in patients with seizures [37] and animal models showed persistent alteration in CAR after epileptic generalized activity [38]. On the opposite, CAR was intact in sedated patients with refractory status epilepticus [39] and during propofol-induced burst-suppression [40]; no specific data on CAR and burst-suppression secondary to severe brain damage has been reported so far. In our cohort, burst-suppression on EEG correlated with higher Mxa at NT. Whether altered CAR is a reflection of deranged metabolism or severe brain damage cannot be determined.

Major strengths of this study are the analysis of a relatively large cohort of patients and the use of a validated approach to assess CAR through spontaneous oscillations in MAP [41]. We systematically evaluated Mxa during HT and at NT, suggesting that time assessment is crucial to understand the role of CAR in CA patients. We should acknowledge also some limitations.
We did not measure directly cerebrovascular resistance or absolute $\mathrm{CBF}$ values nor did we investigate MAP in relation to individual CAR curve. Cerebral perfusion after $\mathrm{CA}$ is probably heterogeneously deranged in the brain, with some areas more affected than others: since we insonated MCA, we cannot exclude that regional alterations in CAR may have gone undetected. Acute brain injury associated with CA may result in a narrowing of the pressure range for CAR, whose the lower limit may be observed at clinically accepted MAP of 60-70 mm Hg [7]. Therefore, we cannot exclude an overestimation of altered CAR in our patients due to the possibility of MAP falling outside the individual range of CAR. Altered CAR at NT could be secondary to an increase in intracranial pressure, which was not directly measured in this study. Cerebral autoregulation may be affected by several factors, such as modifications in the intracranial arteries diameter due to the effect of carbon dioxide arterial partial pressure. However, 45/50 (90\%) of patients in our cohort had $\mathrm{PaCO}_{2}$ in the physiological range of $30-50 \mathrm{mmHg}$ and no relationship was found 
between $\mathrm{PaCO}_{2}$ and Mxa in our cohort (Supplementary material). We defined altered CAR as Mxa $>0.3$. However, such threshold has been used in previous literature and was based on the mathematical definition of moderate correlation. Indeed, Mxa is a continuous index, which likely reflects a continuum in cerebral autoregulation effectiveness [42, 43]. Finally, given the lack of published data on CAR in cardiac arrest patients, we could not properly calculate the sample size of this study and a convenient cohort of 50 patients was selected for this exploratory analysis. All patients who had CPC 5 at 3 months because of brain death or death by other cause were included in non-survivors and unfavourable outcome group. However, multi-organ failure was the cause of death in $8 / 31$ patients (26\%). Multi-organ failure refers to a condition, where more than one organ, system or apparatus is failing, including the brain. In such patients, diagnosis of brain death was not initiated due to the critical general condition. In addition, we only analyzed one fourth of CA patients admitted to our ICU, although most of exclusion criteria were reasonable, and the small sample size may bias statistical modeling. However, the possibility of small sample size bias and overfitting were limited by our modelling $[44,45]$. Nevertheless, caution is advisable with regard to generalizability of our results, which should be confirmed in larger cohort.

\section{Conclusions}

After TTM, cerebral autoregulation is frequently altered in CA during normothermia. Altered CAR during normothermia was independently associated with poor outcomes and other predictors of poor neurological recovery, such as highly malignant patterns on EEG and high NSE values.

\footnotetext{
Abbreviations

ABG: Arterial blood gases; BP: Arterial blood pressure; APACHE II: Acute physiologic assessment and chronic health evaluation; $C A$ : Cardiac arrest; CAR: Cerebral autoregulation; CBF: Cerebral blood flow; CEEG: Continuous electroencephalography; CPC: Cerebral performance category; ECMO: Extra-corporeal membrane oxygenation; EEG: Electroencephalography; $\mathrm{FiO}_{2}$ : Fraction of inspired oxygen; FO: Favourable outcome; FV: Blood flow velocity; HMp: Highly malignant EEG pattern; HT: Hypothermia; IABP: Intra-aortic balIoon counter-pulsation; ICU: Intensive care unit; MAP: Mean systemic arterial pressure; MCA: Middle cerebral artery; Mxa: Mean flow index; NIRS: Near infrared spectroscopy; NMBA: Neuro-muscular blocking agent; NS: Nonsurvivors; NSE: Neuron-specific enolase; NT: Normothermia; PaCO2: Arterial carbon dioxide partial pressure; $\mathrm{PaO}_{2}$ : Oxygen arterial partial pressure; PEEP: Positive end-expiratory pressure; ROSC: Return of spontaneous circulation; $\mathrm{SCVO}_{2}$ : Central venous oxygen saturation; SU: Survivors; TBI: Traumatic brain injury; TCD: Transcranial Doppler; TTM: Targeted temperature management; UO: Unfavourable outcome.
}

\section{Supplementary Information}

The online version contains supplementary material available at https://doi. org/10.1186/s40560-021-00579-z.

Additional file 1: Clinical and biological variables during targeted temperature management; details of outliers; Mxa values comparison among CPC groups; regularized regression models with elastic net; changes in Mxa according to the phase of temperature control; graphical representation of relative weight of tested variables in the predictive models.

\section{Acknowledgements}

Not applicable.

\section{Authors' contributions}

FST and IAC conceived the study protocol; IAC and FZC performed the transcranial Doppler; IAC, SP, AC and FZC collected the data; IAC, FA, HN, SP and FST analyzed the data. IAC, JLV, FA, AC, NG, JC, HN and FST drafted the present manuscript. All authors read and approved the final manuscript.

Funding

Not applicable.

\section{Availability of data and materials}

The data sets used and/or analysed during the current study are available from the corresponding author on reasonable request.

\section{Declarations}

Ethics approval and consent to participate

This study was approved by local Ethics Committee (ref number P2015/394).

The need for informed consent was waived.

\section{Consent for publication}

Not applicable.

\section{Competing interests}

The authors declare that they have no competing interests.

\section{Author details}

${ }^{1}$ Department of Intensive Care, Erasme Hospital, Université Libre de Bruxelles (ULB), Route de Lennik 808, 1070 Bruxelles, Belgium. ${ }^{2}$ Department of Anesthesia and Intensive Care, University Hospital of Foggia, Viale Luigi Pinto 1, 71122 Foggia, Italy. ${ }^{3}$ Department of Neurology, Erasme Hospital, Université Libre de Bruxelles (ULB), Route de Lennik 808, 1070 Bruxelles, Belgium.

Received: 28 June 2021 Accepted: 12 October 2021

Published online: 26 October 2021

References

1. Lancet T. Out-of-hospital cardiac arrest: a unique medical emergency. Lancet. 2018;391(10124):911.

2. Wong MK, Morrison LJ, Qiu F, Austin PC, Cheskes S, Dorian P, et al. Trends in short- and long-term survival among out-of-hospital cardiac arrest patients alive at hospital arrival. Circulation. 2014;130(21):1883-90.

3. Berdowski J, Berg RA, Tijssen JG, Koster RW. Global incidences of out-ofhospital cardiac arrest and survival rates: systematic review of 67 prospective studies. Resuscitation. 2010;81(11):1479-87.

4. Nolan JP, Neumar RW, Adrie C, Aibiki M, Berg RA, Böttiger BW, et al. Postcardiac arrest syndrome: epidemiology, pathophysiology, treatment, and prognostication. A Scientific Statement from the International Liaison Committee on Resuscitation; the American Heart Association Emergency Cardiovascular Care Committee; the Council on Cardiovascular Surgery and Anesthesia; the Council on Cardiopulmonary, Perioperative, and Critical Care; the Council on Clinical Cardiology; the Council on Stroke. Resuscitation. 2008;79(3):350-79. 
5. Sekhon MS, Ainslie PN, Griesdale DE. Clinical pathophysiology of hypoxic ischemic brain injury after cardiac arrest: a "two-hit" model. Crit Care. 2017;21(1):90

6. Nolan JP, Neumar RW, Adrie C, Aibiki M, Berg RA, Bbttiger BW, et al. Postcardiac arrest syndrome: epidemiology, pathophysiology, treatment, and prognostication: a scientific statement from the International Liaison Committee on Resuscitation; the American Heart Association Emergency Cardiovascular Care Committee; the Council on Cardiovascular Surgery and Anesthesia; the Council on Cardiopulmonary, Perioperative, and Critical Care; the Council on Clinical Cardiology; the Council on Stroke (Part II). Int Emerg Nurs. 2010;18(1):8-28.

7. Sundgreen C, Larsen FS, Herzog TM, Knudsen GM, Boesgaard S, Aldershvile J. Autoregulation of cerebral blood flow in patients resuscitated from cardiac arrest. Stroke. 2001;32(1):128-32.

8. Ameloot K, Genbrugge C, Meex I, Jans F, Boer W, Vander Laenen M, et al. An observational near-infrared spectroscopy study on cerebral autoregulation in post-cardiac arrest patients: time to drop 'one-size-fitsall" hemodynamic targets?' Resuscitation. 2015;90:121-6.

9. Callaway CW, Donnino MW, Fink EL, Geocadin RG, Golan E, Kern KB, et al. Part 8: post-cardiac arrest care: 2015 American Heart Association Guidelines update for cardiopulmonary resuscitation and emergency cardiovascular care. Circulation. 2015;132(18 Suppl 2):S465-82.

10. Sandroni C, Combes A, Nolan JP. Focus on post-resuscitation care. Intensive Care Med. 2019;45(9):1283-7.

11. Tzeng YC, Ainslie PN. Blood pressure regulation IX: cerebral autoregulation under blood pressure challenges. Eur J Appl Physiol. 2014;114(3):545-59.

12. Czosnyka M, Smielewski P, Piechnik S, Steiner LA, Pickard JD. Cerebral autoregulation following head injury. J Neurosurg. 2001;95(5):756-63.

13. Budohoski KP, Reinhard M, Aries MJ, Czosnyka Z, Smielewski P, Pickard $J \mathrm{D}$, et al. Monitoring cerebral autoregulation after head injury. Which component of transcranial Doppler flow velocity is optimal? Neurocrit Care. 2012;17(2):211-8.

14. Budohoski KP, Czosnyka M, Kirkpatrick PJ, Smielewski P, Steiner LA, Pickard JD. Clinical relevance of cerebral autoregulation following subarachnoid haemorrhage. Nat Rev Neurol. 2013;9(3):152-63.

15. Pham P, Bindra J, Chuan A, Jaeger M, Aneman A. Are changes in cerebrovascular autoregulation following cardiac arrest associated with neurological outcome? Results of a pilot study. Resuscitation. 2015;96:192-8.

16. Nishizawa $\mathrm{H}$, Kudoh I. Cerebral autoregulation is impaired in patients resuscitated after cardiac arrest. Acta Anaesthesiol Scand. 1996:40(9):1149-53.

17. Sekhon MS, Gooderham P, Menon DK, Brasher PMA, Foster D, Cardim D, et al. The Burden of brain hypoxia and optimal mean arterial pressure in patients with hypoxic ischemic brain injury after cardiac arrest. Crit Care Med. 2019:47(7):960-9.

18. Naqvi J, Yap KH, Ahmad G, Ghosh J. Transcranial Doppler ultrasound: a review of the physical principles and major applications in critical care. Int J Vasc Med. 2013;2013:629378

19. Hirsch LJ, LaRoche SM, Gaspard N, Gerard E, Svoronos A, Herman ST, et al. American clinical neurophysiology society's standardized critical care EEG terminology: 2012 version. J Clin Neurophysiol. 2013;30(1):1-27.

20. Backman S, Cronberg T, Friberg H, Ullén S, Horn J, Kjaergaard J, et al. Highly malignant routine EEG predicts poor prognosis after cardiac arrest in the target temperature management trial. Resuscitation. 2018;131:24-8.

21. Westhall E, Rosén I, Rossetti AO, van Rootselaar AF, Kjaer TW, Horn J, et al. Electroencephalography (EEG) for neurological prognostication after cardiac arrest and targeted temperature management; rationale and study design. BMC Neurol. 2014;14:159.

22. Lang EW, Lagopoulos J, Griffith J, Yip K, Mudaliar Y, Mehdorn HM, et al. Noninvasive cerebrovascular autoregulation assessment in traumatic brain injury: validation and utility. J Neurotrauma. 2003;20(1):69-75.

23. Park MY, Hastie T. Penalized logistic regression for detecting gene interactions. Biostatistics. 2008;9(1):30-50.

24. Friedman J, Hastie T, Tibshirani R. Regularization paths for generalized linear models via coordinate descent. J Stat Softw. 2010;33(1):1-22.

25. Sekhon MS, Smielewski P, Bhate TD, Brasher PM, Foster D, Menon DK, et al. Using the relationship between brain tissue regional saturation of oxygen and mean arterial pressure to determine the optimal mean arterial pressure in patients following cardiac arrest: a pilot proof-of-concept study. Resuscitation. 2016;106:120-5.

26. Stammet P, Collignon O, Hassager C, Wise MP, Hovdenes J, Åneman A, et al. Neuron-specific enolase as a predictor of death or poor neurological outcome after out-of-hospital cardiac arrest and targeted temperature management at $33^{\circ} \mathrm{C}$ and $36^{\circ} \mathrm{C}$. J Am Coll Cardiol. 2015;65(19):2104-14.

27. Bhate TD, McDonald B, Sekhon MS, Griesdale DE. Association between blood pressure and outcomes in patients after cardiac arrest: a systematic review. Resuscitation. 2015;97:1-6.

28. Iida K, Satoh H, Arita K, Nakahara T, Kurisu K, Ohtani M. Delayed hyperemia causing intracranial hypertension after cardiopulmonary resuscitation. Crit Care Med. 1997;25(6):971-6.

29. Lemiale V, Huet O, Vigué B, Mathonnet A, Spaulding C, Mira JP, et al. Changes in cerebral blood flow and oxygen extraction during postresuscitation syndrome. Resuscitation. 2008;76(1):17-24.

30. Buunk $G$, van der Hoeven JG, Meinders AE. Cerebral blood flow after cardiac arrest. Neth J Med. 2000:57(3):106-12.

31. Alvarez-Fernández JA, Pérez-Quintero R. Use of transcranial Doppler ultrasound in the management of post-cardiac arrest syndrome. Resuscitation. 2009;80(11):1321-2.

32. van den Brule JM, Vinke E, van Loon LM, van der Hoeven JG, Hoedemaekers CW. Middle cerebral artery flow, the critical closing pressure, and the optimal mean arterial pressure in comatose cardiac arrest survivors-an observational study. Resuscitation. 2017;110:85-9.

33. Lee JK, Brady KM, Mytar JO, Kibler KK, Carter EL, Hirsch KG, et al. Cerebral blood flow and cerebrovascular autoregulation in a swine model of pediatric cardiac arrest and hypothermia. Crit Care Med. 2011;39(10):2337-45.

34. Lavinio A, Timofeev I, Nortje J, Outtrim J, Smielewski P, Gupta A, et al. Cerebrovascular reactivity during hypothermia and rewarming. Br J Anaesth. 2007:99(2):237-44.

35. Paulson OB, Strandgaard S, Edvinsson L. Cerebral autoregulation. Cerebrovasc Brain Metab Rev. 1990;2(2):161-92.

36. Volnova A, Tsytsarev V, Ptukha M, Inyushin M. In vitro and in vivo study of the short-term vasomotor response during epileptic seizures. Brain Sci. 2020;10(12).

37. Lv S, Guo ZN, Jin H, Sun X, Jia M, Ma H, et al. Compromised dynamic cerebral autoregulation in patients with epilepsy. Biomed Res Int. 2018;2018:6958476

38. Hascoet JM, Monin P, Vert P. Persistence of impaired autoregulation of cerebral blood flow in the postictal period in piglets. Epilepsia. 1988:29(6):743-7.

39. Meyer M, Juenemann M, Braun T, Schirotzek I, Schramm P. Intact cerebrovascular autoregulation in patients with refractory status epilepticus due to sufficient anesthetic treatment on a neurointensive care unit: a prospective cohort study. Crit Care. 2019;23(1):6.

40. Matta BF, Lam AM, Strebel S, Mayberg TS. Cerebral pressure autoregulation and carbon dioxide reactivity during propofol-induced EEG suppression. Br J Anaesth. 1995;74(2):159-63.

41. Czosnyka M, Miller C. Monitoring PitIMCCoM. Monitoring of cerebral autoregulation. Neurocrit Care. 2014;21(Suppl 2):S95-102.

42. Sorrentino E, Diedler J, Kasprowicz M, Budohoski KP, Haubrich C, Smielewski P, et al. Critical thresholds for cerebrovascular reactivity after traumatic brain injury. Neurocrit Care. 2011;16(2):258-66.

43. Liu X, Czosnyka M, Donnelly J, Budohoski KP, Varsos GV, Nasr N, et al. Comparison of frequency and time domain methods of assessment of cerebral autoregulation in traumatic brain injury. J Cerebral Blood Flow Metab. 2014;35(2):248-56.

44. Vittinghoff $E, M c C u l l o c h ~ C E$. Relaxing the rule of ten events per variable in logistic and Cox regression. Am J Epidemiol. 2007;165(6):710-8.

45. Corcoran C, Mehta C, Patel N, Senchaudhuri P. Computational tools for exact conditional logistic regression. Stat Med. 2001;20(17-18):2723-39.

\section{Publisher's Note}

Springer Nature remains neutral with regard to jurisdictional claims in published maps and institutional affiliations. 